\title{
UMA PROPOSTA DIDÁTICA PARA O ENSINO DE ESTATÍSTICA: O USO DO EXCEL PARA REPRESENTAÇÃO GRÁFICA
}

\author{
Daiani Finatto Bianchini-IFF-daiani.bianchini@iffarroupilha.edu.br \\ Cleber Bisognin - IME - UFRGS - cbisognin@ufrgs.br \\ Débora da Silva Soares - IME - UFRGS - debora.soares@ufrgs.br
}

\begin{abstract}
Resumo: Este estudo discute a Educação Estatística e tem como objetivo analisar as possibilidades e limites de uma proposta que inclui os estudos da representação gráfica, realizada por alunos do Ensino Fundamental, utilizando o software Excel. As análises resultantes desta investigação evidenciam que o campo estatístico precisa ser consolidado no espaço escolar. Os resultados sugerem que os alunos apreciam e se envolvem em propostas que tomam como ponto de partida a coleta e análise dos dados, isto é, aprender estatística "fazendo estatística" é uma necessidade. As dificuldades encontradas devemse, em grande parte, à falta de conhecimento relativo aos conceitos estatísticos e ao software utilizado. Apesar disso, o Excel foi um recurso que potencializou as relações entre as variáveis envolvidas, dando ênfase a um trabalho interpretativo e reflexivo, a partir da compreensão da realidade.
\end{abstract}

Palavras-chave: Educação Estatística; Investigação; Tecnologias Digitais.

\section{A PROPOSAL FOR TEACHING STATISTICS EDUCATION: USING EXCEL FOR GRAPHIC REPRESENTATION}

\begin{abstract}
This study discusses the Statistics Education and aims to analyze the possibilities and limits of a teaching proposal, which includes the graphical representation studies, done by elementary school students, using the Excel software. The analysis and results of this research have evidenced that it is necessary to consolidate the statistical field in the school environment. The results suggest that the students appreciate and engage themselves in proposals which take data collection and analysis as starting point, that is, learning statistics "doing statistics" is a demand. The difficulties encountered are, mainly, due to the lack of relative knowledge on statistical concepts and about the software used. Nevertheless, the Excel software as a resource that contributed to the extent that we can enhance the relations among the variables involved in the study, giving emphasis to an interpretative and reflective work from the understanding of the expressed reality. Therefore, a purposeful planning of the teacher in a problem-solving perspective, and in a contextualized and investigative work, is necessary.
\end{abstract}

Keywords: Statistics Education; Survey; Digital Technologies.

\section{Introdução}

O conhecimento estatístico tem se destacado nos currículos oficiais da matemática nos últimos anos. Segundo o PCN (BRASIL, 1997), o conteúdo de estatística integra o bloco denominado "Tratamento da Informação" que, juntamente com os blocos "Números e Operações", "Grandezas e Medidas" e "Espaço e Forma", contemplam a área da matemática no ensino fundamental.

O Tratamento da Informação, desenvolvido de forma bastante tímida nos currículos anteriores, ganha a partir deste documento status de bloco de conteúdos, sendo justificado especialmente por sua demanda social, por se tratar de conhecimentos recorrentes na 
sociedade atual, podendo ser um importante instrumento para se desenvolver a cidadania, através de estudos referentes à estatística, probabilidade e combinatória. Para o desenvolvimento da cidadania ${ }^{1}$, no entanto, entende-se que é necessário não somente tomar conhecimento e saber manipular os dados produzidos a partir de situações reais, mas também interpretar criticamente o que os valores dizem, possibilitando, assim, desenvolver uma ação reflexiva e crítica no grupo social no qual estamos inseridos. Essa proposta remete à ação ativa dos sujeitos envolvidos no processo educativo, destacando a importância de uma proposta de trabalho que envolva situações contextualizadas e problematizadoras. Conforme afirma Lopes (2008, p. 58), “[...] é essencial o desenvolvimento de atividades que partam sempre de problematização, pois assim como os conceitos matemáticos, os estatísticos também devem ser inseridos em situações vinculadas ao cotidiano deles [dos alunos]".

Corroborando com os estudos de Lopes (2008), Campos, Wodewotzki e Jacobini (2011) propõem uma aproximação da Educação Crítica com o ensino da Estatística, construindo o que chamam de Teoria da Educação Estatística Crítica. Para esses autores, os problemas de Estatística devem começar com um questionamento e terminar com uma opinião que, se espera, seja fundamentada em resultados. Para isso, o trabalho com Estatística em sala de aula deveria promover discussões e reflexões para a solução de uma situação-problema que seja levantada pela classe ou instigada pelo professor.

Reconhecendo a potencialidade deste trabalho, faz-se necessário conhecer e ousar em novas propostas que contemplem as especificidades deste campo do conhecimento. $\mathrm{O}$ fato de a Estatística integrar a área de Matemática pode levar-nos a pensá-la como um conhecimento matemático, aproximando-a dos demais campos, como a geometria, a álgebra, a aritmética, pois seu instrumento principal são as informações numéricas. É importante, no entanto, que se busque caracterizar a Estatística no ambiente escolar, fazendo distinções entre ela e os demais campos matemáticos, uma vez que, apesar de conjugarem aspectos comuns, apresentam diferenças importantes.

A aleatoriedade e a incerteza, características do pensamento estatístico, distanciamse dos aspectos lógicos e determinísticos dos demais campos matemáticos. A subjetividade na escolha da forma de organização dos dados, da interpretação e reflexão, a análise e a tomada de decisão fazem com que a Estatística apresente um foco diferenciado dentro da área de Matemática.

Além disso, os problemas estatísticos costumam ser abertos, isto é, pode existir mais de um método de solução correta, ou ainda a solução ou previsão pode não se concretizar. O desenvolvimento de um trabalho mais focado no processo (produção, análise, tomada de decisão) do que no produto final (respostas certas ou erradas) reforça a ideia de que, mesmo sendo entendida no ambiente escolar como um campo de estudo da Matemática, a Estatística tem características diferenciadas, que precisam ser reconhecidas e potencializadas. Para Lopes (2010, p.55):

[...] o fundamental nos problemas de Estatística é que, pela sua natureza, não têm uma solução única e não podem ser avaliados como totalmente errados ou certos, devendo ser avaliados em termos da qualidade do raciocínio, da adequação dos métodos utilizados à natureza dos dados existentes.

Estudos recentes têm mostrado que a utilização das tecnologias para a consolidação do ensino e aprendizagem de Estatística pode ser um caminho interessante para

\footnotetext{
${ }^{1}$ Assume-se aqui o entendimento de Lopes (2004, p. 19), que compreende cidadania como "a capacidade de atuação reflexiva, ponderada e crítica de um indivíduo em seu grupo social”.
} 
desenvolver, especialmente, a análise crítica a respeito dos dados produzidos. Nessa perspectiva, Cobb (apud Estevam e Kalinke, 2013, p.106), sustenta que os computadores nos libertam para que possamos analisar dados reais com mais ênfase na interpretação do que nos cálculos, com vistas a priorizar as ideias de produção de dados aleatórios junto com a análise, com a inferência desses dados e com menor ênfase aos mecanismos das resoluções. Segundo os $\mathrm{PCN}+{ }^{2}$ (BRASIL, 2002, p.229-230),

\begin{abstract}
A escola não pode ficar alheia ao universo informatizado se quiser, de fato, integrar o estudante ao mundo que o circunda, permitindo que ele seja um indivíduo autônomo, dotado de competências flexíveis e apto a enfrentar as rápidas mudanças que a tecnologia vem impondo à contemporaneidade (Brasil, 2002, p. 229-230).
\end{abstract}

Ainda, segundo Pastorio e Sauerwein (2015)“as Tecnologias de Informação e Comunicação (TIC) são acessíveis a grande maioria da população, oferecem um acesso à informação diário e atualizado, o que pode mudar a forma com que o aluno estuda e aprende". O dinamismo, a velocidade e a crescente quantidade de novos softwares, que permitem explorar todos os aspectos do processamento de dados, justificam a pertinência das TIC no trabalho com Probabilidade e Estatística e possibilitam agregar novos tópicos ao ensino deste campo.

Ainda segundo Estevam e Kalinke (2013, p.106), a escolha de uma ferramenta tecnológica em particular deve ser feita com base na facilidade de uso, interatividade, ligações dinâmicas entre dados-gráficos-análises e, um último aspecto, relacionado à portabilidade. Boas escolhas podem favorecer a colaboração entre os alunos e as interações entre alunos e professor. Além disso, muitas vezes pode ser necessária uma combinação de várias ferramentas diferentes para se atingir determinados objetivos. Os resultados desta pesquisa destacam que, mais importante que as características que o software apresenta para abordagem de conceitos estatísticos e probabilísticos, é o modo como se planeja, executa e avalia tarefas explorando diferentes ambientes, a partir de objetivos específicos claros traçados inicialmente. Neste contexto, Coutinho, et al. (2012), apresentam a construção de um tutorial para professores do ensino fundamental, utilizando o GeoGebra na construção e interpretação de gráficos. Segundo os autores, o tutorial tem como objetivo inserir o software nas aulas, favorecendo o desenvolvimento estatístico dos alunos.

Com base nos diferentes referenciais apresentados até o momento, buscou-se responder ao seguinte questionamento: Quais os limites e as possibilidades observadas em uma prática de educação estatística realizada no Ensino Fundamental mediada por recursos tecnológicos? $\mathrm{Na}$ tentativa de refletir a respeito deste questionamento, elaboramos, registramos e analisamos uma investigação pautada na metodologia da engenharia didática, a qual será descrita a seguir.

\title{
2 A Realidade Vivenciada e o Percurso Metodológico Proposto
}

A proposta metodológica que sustenta este estudo está pautada na engenharia didática que, para Carneiro (2005), pode ser vista como referencial para o desenvolvimento de produtos para o ensino, gerados na junção do conhecimento prático com o conhecimento teórico.

Além disso, Silva, Barone e Basso (2014), afirmam que:

\footnotetext{
${ }^{2}$ Orientações Educacionais Complementares aos Parâmetros Curriculares Nacionais (PCN).
} 


\begin{abstract}
Acreditamos que a engenharia didática possibilita ao professor repensar a sua prática docente enquanto atua em sala de aula e também nota-se que a realidade escolar torna-se cenário para reflexão, criação e encaminhamento de propostas inovadoras de ensino. Ao trabalhar utilizando esse método de ensino o professor pode se questionar se é possível que os alunos aprendam determinado conteúdo através de uma sequência de atividades que pode ser repensada e readequada durante a execução da proposta.
\end{abstract}

Nessa linha, a prática de ensino é articulada como uma prática de investigação. A Engenharia Didática propõe algumas etapas de desenvolvimento, as quais delineiam os contornos da investigação: a delimitação do tema, a análise prévia em suas dimensões epistemológicas, didática e cognitiva, a formulação de hipóteses, a experimentação e a validação.

Desta forma, buscamos uma proposta de ensino para o estudo de conceitos básicos de Estatística que utilize um recurso computacional bastante conhecido, o Excel. Antes de colocá-la em prática, porém, buscamos conhecer a forma como o campo estatístico vem sendo desenvolvido na rede de ensino onde a pesquisa foi desenvolvida. Iniciamos pela análise do Plano de Estudos e de alguns livros didáticos disponíveis para consulta na escola, especialmente o livro disponível para os alunos, Andrini e Vasconcelos (2012). Nesta etapa de análise, foi possível perceber que os conceitos relacionados à Estatística são apresentados de forma bastante superficial, iniciando com conceitos básicos, explorando diferentes tipos de gráficos para a interpretação de dados, muitas vezes, descontextualizados.

Para realizar a proposta de trabalho, consideramos que o ensino de Estatística está primeiramente relacionado a um contexto de pesquisa, de produção de dados em um processo investigativo e baseamos nosso trabalho em Lopes (2004). A autora sugere que a ação pedagógica passe por algumas etapas, dinâmica esta que exige a participação ativa do aluno no processo. A Figura 1 a seguir ilustra o processo de tratamento de dados sugerido por Lopes (2004, p. 195).

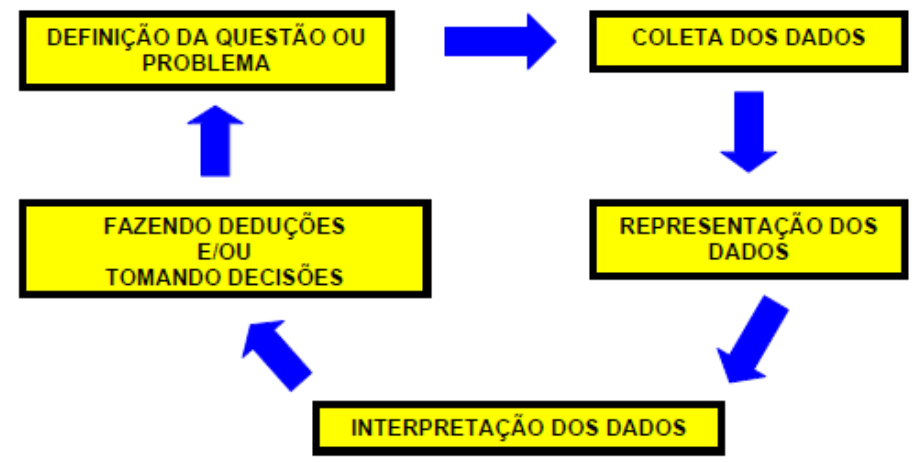

Figura 1 - Processo do tratamento de dados. Fonte: Lopes (2004, p. 195).

Com o referencial metodológico e os princípios do trabalho definidos, iniciamos a investigação. A etapa inicial foi questionar o grupo de alunos acerca de seu conhecimento sobre Estatística. Para isto, elaborou-se um instrumento denominado de "Análise Prévia". Este instrumento foi composto de três questões interpretativas. A análise deste instrumento nos permitiu perceber dificuldades por parte dos alunos na compreensão de conceitos estatísticos.

A partir deste instrumento, propomos aos alunos a vivência de um processo investigativo que teve como base uma pesquisa estatística. Conforme Lopes (2004), o primeiro momento deste processo é a definição do problema. A pesquisa propunha 
investigar o perfil dos alunos integrantes do $9^{\circ}$ ano de uma escola de Ensino Fundamental do Estado do Rio Grande do Sul, a partir do preenchimento de um questionário. Este instrumento foi elaborado considerando características pessoais (idade, massa, altura, gênero...) e questões relacionadas a gostos e preferências da turma (preferência musical, esportivas, atividades de lazer, entre outras). As questões foram elaboradas considerando a intencionalidade do trabalho da professora com sugestões dos alunos.

Com os questionários em mãos, respondidos e numerados, foi possível proceder à organização das informações. A turma foi dividida em 3 grupos. Cada grupo ganhou uma planilha em branco, sendo que cada grupo tinha a tarefa de preencher a planilha com as informações dos questionários. Para dinamizar e propiciar maior significado a todo este processo, as informações organizadas foram transferidas para uma planilha eletrônica (banco de dados), para então ser realizada a terceira parte do processo: a representação dos dados, que diz respeito à representação gráfica seguida da análise.

A partir dos conceitos básicos desenvolvidos em sala de aula, propusemos atividades a serem desenvolvidas no laboratório de informática, utilizando o software Excel. Para isto, elaboramos um material com orientações iniciais gerais sobre o software e discriminamos os tipos de representações (gráficos) a serem construídas com as respostas de cada questão já tabuladas no banco de dados. Na continuidade, explicitaremos com mais detalhes a realização deste trabalho, tecendo análises sobre o seu desenvolvimento, destacando as hipóteses inicias, os aspectos positivos e pontos a serem repensados.

\section{Tecendo Análises, Buscando Entendimentos}

Nesta seção buscaremos compreender, a partir da prática vivenciada, alguns possíveis caminhos para o estudo da Estatística no Ensino Fundamental, especialmente quando pensamos seu estudo subsidiado por um recurso tecnológico. Essa proposta foi considerar algumas das hipóteses construídas em relação ao trabalho antes de desenvolvêlo, analisando-as, exemplificando-as e verificando sua veracidade a partir do que foi possível desenvolver com as turmas do $9^{\circ}$ ano, sob a regência da Professora Daiani Finatto Bianchini.

A primeira hipótese considerada na construção da proposta de trabalho foi que $o s$ alunos do $9^{\circ}$ ano têm noções básicas de informática e que, portanto, teriam facilidade em compreender o Excel, desenvolvendo as atividades de forma tranquila. Esta hipótese surgiu no momento em que considerou-se que esta geração de estudantes se desenvolve, desde a infância, imersa em tecnologia e, por isto, tem grande facilidade em compreender seu mecanismo de funcionamento.

A ideia de que os alunos "dominam" o meio tecnológico é, muitas vezes, o que limita o uso de computadores como um recurso em sala de aula, uma vez que, em geral, os professores sentem-se muito limitados, o que pode deixar transparente, diante dos alunos, as suas fragilidades. Esta, porém, não foi uma hipótese confirmada durante a realização da prática. Observou-se uma dificuldade inicial com o Excel, pois nenhum aluno das turmas onde a prática foi desenvolvida conhecia o software. Isto demandou um trabalho ainda mais direcionado, com explicações iniciais sobre o seu funcionamento e elaboração de orientações escritas para as atividades propostas.

O trabalho foi desenvolvido em duplas, ocupando um total de 6 horas/aula. No primeiro encontro, com o tempo de duração de 2 horas/aula, o objetivo foi mostrar o funcionamento do Excel, utilizando a nomenclatura própria para o seu uso como: células, linhas, colunas, ícones, barra de ferramentas, eixo horizontal, eixo vertical, rótulos de linha e de coluna. Construir uma tabela simples, ensinando-os a trabalhar com a ferramenta "tabela dinâmica" também foi um objetivo, selecionando os dados necessários 
à produção da tabela, formatando o campo de valor, mostrando o valor em porcentagem e finalizando a construção de uma tabela simples com os elementos e com o aspecto estudado em aula. Na Tabela 1, pode-se verificar a finalização deste processo. A tabela foi construída por uma dupla de alunos, onde FA denota frequência absoluta e FR denota frequência relativa.

Tabela 1 - Gênero dos alunos do $9^{\circ}$ Ano.

Fonte: Construção realizada em sala de aula.

\begin{tabular}{ccc} 
Gênero & FA & FR \\
\hline Feminino & 12 & $57,14 \%$ \\
\hline Masculino & 9 & $42,86 \%$ \\
\hline Total Geral & $\mathbf{2 1}$ & $\mathbf{1 0 0 , 0 0 \%}$ \\
\hline
\end{tabular}

Esta não foi uma tarefa fácil, pois os alunos precisavam entender a terminologia utilizada. Ao explicar o procedimento foi preciso utilizar termos nem sempre conhecidos, conforme verificado no excerto a seguir:

Precisamos selecionar os dados que estão na planilha, clicar em inserir tabela dinâmica, selecionar do conjunto de dados a variável que desejamos colocar na tabela e arrastar até o rótulo de linhas, o que produzirá a distribuição dos dados nas linhas. Arrastaremos a mesma variável ao campo de valores. Faremos este procedimento duas vezes, pois queremos que a contagem seja em número absolutos (FA) e em porcentagem (FR). É preciso transformar os resultados dados em números para porcentagem formatando o campo de valor. Utilizando o ícone do somatório, fazer o cálculo do total em número e em porcentagem. Professora Daiani Finatto Bianchini,

Apenas no desenvolvimento da atividade, durante a explicação, que percebeu-se o quanto estes termos não faziam sentido para os alunos. Com as imagens do programa sendo projetadas no data show, discutiu-se com as duplas o significado de cada termo e qual o sentido em fazer tais procedimentos. É interessante refletir, neste momento, sobre a insegurança que, muitas vezes, demonstramos com o uso do computador como um recurso tecnológico nas aulas de Matemática. No laboratório de informática ficou claro o fundamental papel do professor como orientador da aprendizagem, afinal os conceitos a serem desenvolvidos na atividade proposta devem estar minuciosamente planejados pelo professor e mesmo que haja algum contratempo em relação ao software, o domínio conceitual do que se deseja ensinar é função do professor. Da mesma forma, devemos ter em mente que o uso do computador sem a compreensão dos conceitos teóricos tem pouca validade, portanto, a participação ativa, questionadora, problematizadora do professor, faz-se fundamental.

No segundo encontro, com duração de 2 horas/aula, nosso objetivo foi, a partir da construção das tabelas, construir diferentes tipos de gráficos que expressariam os resultados das diferentes variáveis que compunham a pesquisa. Iniciamos este encontro retomando os conhecimentos desenvolvidos na primeira aula.

A partir da tabela construída, os alunos foram orientados a selecionar apenas a coluna da frequência absoluta, na intenção de que os gráficos ficassem "limpos" e com apenas as informações necessárias para a compreensão dos dados. Foram explorados diferentes tipos de gráficos tais como: colunas, barras, linhas e setores. Os alunos exploraram diferentes possibilidades e foram muito criativos nesta produção.

As dificuldades associadas a este trabalho, novamente ficaram concentradas na terminologia relacionada ao programa e à Estatística. Com os dados selecionados foi preciso escolher o tipo e formato do gráfico. Utilizando a ferramenta layout foi possível 
introduzir o título do gráfico, o título dos eixos, excluir linhas de grade ou acrescentar rótulos. Estes elementos dão significado e contribuem para a compreensão dos gráficos pelo leitor. Percebeu-se que os alunos não relacionavam o significado de "título do eixo horizontal" como o eixo onde deveríamos inserir a variável, em um gráfico de colunas verticais, por exemplo. A pergunta recorrente nesta fase do trabalho foi: "Então professora, o que eu coloco aqui?" (no eixo horizontal). Foi preciso retomar o significado dos eixos, o que expressavam para que as duplas soubessem, sem ganhar a resposta pronta, nomear o eixo horizontal.

\begin{tabular}{ccc}
\hline $\begin{array}{c}\text { ATIVIDADES } \\
\text { FíSICAS }\end{array}$ & FA & FR(\%) \\
\hline ARTES MARCIAIS & 1 & $4,55 \%$ \\
BASQUETE & 4 & $18,18 \%$ \\
CICLISMO & 1 & $4,55 \%$ \\
DANCCA & 3 & $13,64 \%$ \\
FUTEBOL & 9 & $40,91 \%$ \\
MUSCULAÇ̃̃O & 1 & $4,55 \%$ \\
NENHUM & 2 & $9,09 \%$ \\
VÔLEI & 1 & $4,55 \%$ \\
\hline TOtal & 22 & $100,00 \%$ \\
\hline
\end{tabular}

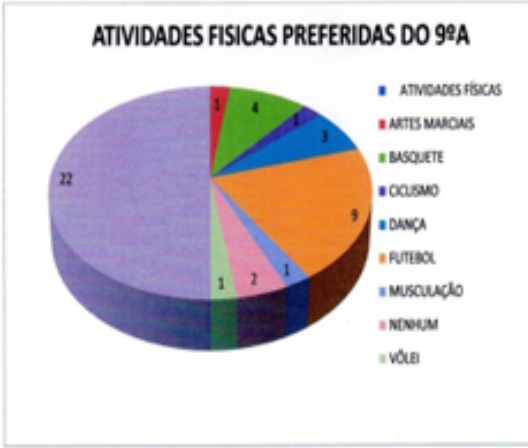

Figura 2 - Tabelas e Gráfico de setores produzido pelos alunos, referente a atividade física preferida. Fonte: Trabalho avaliativo dos alunos.

Um erro bastante comum na produção dos gráficos foi a seleção da linha do total como sendo um dos dados do gráfico. Quando produziam um gráfico de setores selecionando, inclusive, a linha do total, o software construía uma imagem totalmente sem relação com os dados reais. Foi o que aconteceu na produção de uma dupla, conforme apresentado na Figura 2.

Na tabela construída pelos alunos, o total de entrevistados foi 22, porém a soma das fatias do gráfico de setores produzido pela dupla foi de 44 entrevistados. Apesar da dupla produzir uma análise sobre esta variável, o equívoco não foi percebido.

O terceiro e último encontro, com duração de 2 horas/aula, teve como objetivo avançar nos conhecimentos desenvolvidos nas aulas anteriores, propondo o estudo de tabelas e gráficos de dupla entrada, podendo, assim, comparar duas variáveis.

Em um primeiro momento focou-se na interpretação dos tipos de variáveis que compunham a pesquisa, buscando as variáveis em que havia sentido fazer a comparação. Desta forma, houve o entendimento de que seria interessante comparar "atividade de lazer preferida" com a variável "gênero", pois assim estaríamos buscando conhecer quais as atividades mais ou menos preferidas entre o grupo de meninas e de meninos. Por outro lado, não havia sentido relacionar "Atividade de lazer preferida" com o "número de irmãos"; apesar de ser algo possível, não é algo que nos ajuda a compreender o perfil da turma. A Tabela 2 e a Figura 3 apresentam o resultado do trabalho desenvolvido por uma dupla do $9^{\circ}$ ano, na qual foram relacionadas as variáveis Estilos musicais preferidos e Gênero.

O terceiro encontro foi o mais tranquilo e o mais produtivo. Os alunos já tinham criado uma "intimidade" com o programa, sabiam produzir tabelas e gráficos, e as dificuldades iniciais haviam sido superadas. Apenas na terceira aula conseguimos perceber de forma clara e positiva duas importantes hipóteses referentes à proposta metodológica que tínhamos no início do trabalho:

O trabalho com o Excel contribuirá positivamente para a aprendizagem dos conceitos estatísticos, permitindo que a ênfase do trabalho seja a análise dos dados e; 
Haverá maior motivação e compreensão do estudo da Estatística após o trabalho com o software.

Tabela 2 - Tabela comparativa - Estilo musical preferido e gênero. Fonte: Construção realiza em sala de aula.

\begin{tabular}{|cccc|} 
Estilo Musical & Feminino & Masculino & $\begin{array}{c}\text { Total } \\
\text { Geral }\end{array}$ \\
\hline Rock & 1 & & 1 \\
Funk & 1 & 5 & 1 \\
Sertanejo & 5 & 1 & 10 \\
Nativista & & 1 & 1 \\
Gospel & & 2 & 1 \\
Outros & 5 & $\mathbf{9}$ & 7 \\
\hline Total Geral & $\mathbf{1 2}$ & $\mathbf{2 1}$
\end{tabular}

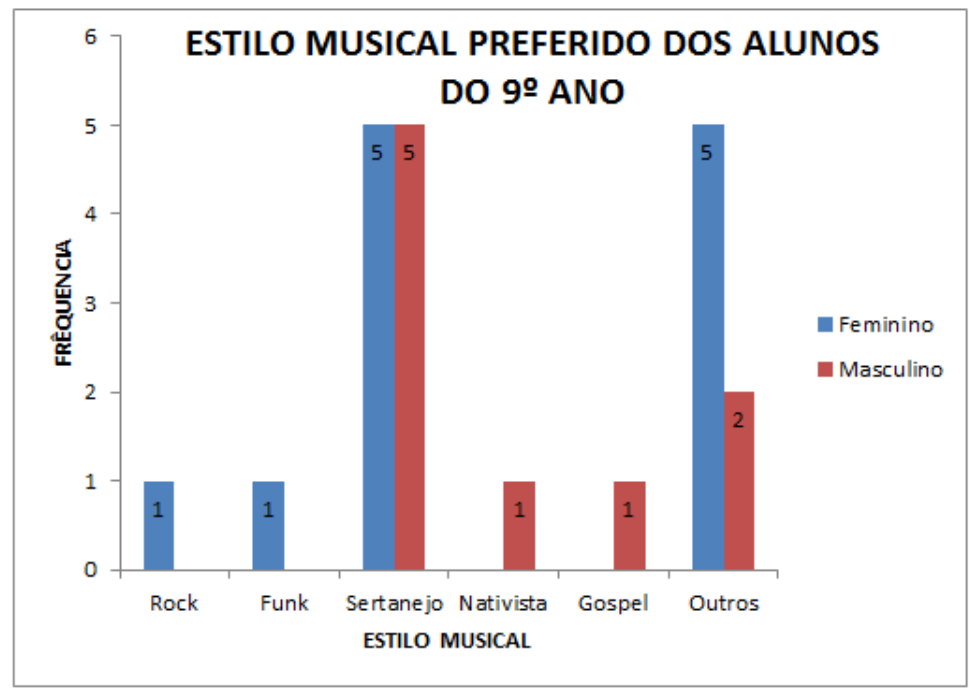

Figura 3 - Gráfico de colunas duplas.

Fonte: Resolução apresentada por uma dupla a uma questão da prova trimestral.

No terceiro encontro, o trabalho fluiu praticamente sem a intervenção docente. Os alunos já sabiam o que precisavam fazer e como desenvolver a atividade. Houve interação entre as duplas, que se movimentaram na sala para ver o resultado do trabalho dos colegas. As duplas mais próximas conseguiram se ajudar e trocaram opiniões sobre as diferentes formas de expressar os resultados nos gráficos. Ao final do terceiro encontro, foi encaminhado um trabalho avaliativo, a ser realizado nas duplas, onde os alunos tiveram que produzir tabelas, gráficos e análises de algumas variáveis não exploradas em aula.

A atividade avaliativa em forma de trabalho teve como objetivo expandir o que já havia sido desenvolvido em aula para outras variáveis da nossa pesquisa. Foi solicitado que houvesse uma introdução, uma conclusão e a análise de cada uma das representações gráficas. Nossa intenção foi que os alunos conseguissem, a partir dos dados analisados, chegar a algumas conclusões a respeito do perfil da turma e conseguissem expressar tais ideias em forma de um relatório.

Como era de se esperar, os alunos apresentaram dificuldades para desenvolver esta atividade. As dificuldades estiveram, especialmente, em nível de registro escrito daquilo que estavam percebendo nas representações gráficas. A expectativa era que os alunos apresentassem uma inter-relação entre as inúmeras variáveis estudadas na pesquisa, o que não pode ser percebido no registro escrito, conforme encontra-se nos excertos abaixo. $\mathrm{Na}$ 
Figura 4 é possível perceber através do relato escrito dos alunos, uma leitura superficial dos dados, onde poucas variáveis do estudo são citadas. As variáveis citadas por sua vez, são apenas apresentadas não havendo uma análise das influências que produziram tais dados.

\begin{abstract}
O estudo sobre estatística teve início no dia 17/04/2015, a partir desse dia começamos a discussão sobre esse assunto na turma, tivemos explicações sobre os diversos tipos de gráficos e tabelas. Junto com a discussão damos início à uma pesquisa com os alunos do $9^{\circ} \mathrm{B}$, essa pesquisa foi feita para conhecer melhor os alunos.

Após as discussões, explicações, a pesquisa feita na turma e as atividades elaboradas no laboratório de informática, damos início ao trabalho de Estatística. Esse trabalho foi feito de acordo com uma pesquisa feita na turma. Nele desenvolvemos seis tabelas e seis gráficos cada um com sua análise, de acordo com as questões respondidas pelos alunos na pesquisa. As questões eram sobre o que os alunos mais gostavam de fazer, gosto musical, atividade física preferida, entre outras. As tabelas e os gráficos foram feitos no programa Excel, no computador.

A partir da pesquisa e do trabalho de Estatística podemos concluir que a maioria dos alunos do $9^{\circ} \mathrm{B}$ tem a mesma idade, também tem como gosto musical preferido Sertanejo. Com esse trabalho nós conhecemos melhor o perfil dos nossos colegas, e serviu também como grande aprendizado em Estatística.
\end{abstract}

Figura 4 - Excerto da conclusão de um dos trabalhos desenvolvidos pelos alunos do $9^{\circ}$ ano. Fonte: Trabalho avaliativo realizado pelos alunos do $9^{\circ}$ ano.

Esta proposta de trabalho, onde os alunos têm participação ativa e na qual buscamos um relatório de trabalho, tenta romper, parcialmente, com aquilo que geralmente é nossa prática dentro da disciplina de matemática. A "estranheza" demonstrada pelos alunos é algo que também precisa ser trabalhado, afinal não é tão frequente a proposta de atividades nas quais os alunos precisam registrar de forma escrita a sua argumentação.

A Figura 4 expressa, de forma parcial, a análise conclusiva solicitada no trabalho avaliativo realizado pelos alunos.

A última hipótese considerada ao iniciarmos a pesquisa foi que ao final do trabalho do Excel os alunos terão maior clareza para interpretar questões relativas à Estatística.

O trabalho realizado ao final da proposta de ensino e também avaliação trimestral marcaram momentos avaliativos que confirmaram o que já havíamos percebido no decorrer das aulas. A compreensão em relação aos termos e ao entendimento dos conceitos introdutórios da Estatística avançaram consideravelmente, o que sugere a validade da hipótese acima. A escrita, a argumentação e a inter-relação entre as variáveis estudadas, no entanto, precisam ser ainda muito estimuladas, o que sugere um trabalho sistemático para que tais conhecimentos sejam consolidados. No nosso ponto de vista, é uma consequência das opções metodológicas de trabalho com o bloco "Tratamento da Informação" que, na maioria das vezes, prioriza a leitura de gráficos e tabelas em contextos desconhecidos, sem proposição de uma leitura que vá além dos dados explícitos nos gráficos.

\title{
Considerações Finais
}

A Educação Estatística é um campo ainda em consolidação no currículo da Educação Básica, especialmente porque é uma temática não vivenciada pela maioria dos professores enquanto estudantes em cursos de licenciatura. A inserção deste campo nos PCN (BRASIL, 1997), $\mathrm{PCN}^{+}$(BRASIL, 2002), nos materiais de apoio pedagógicos como 
livros didáticos e nas avaliações externas sugerem que o trabalho seja implementado, porém, não há compreensão por parte dos professores em como isto pode acontecer. Como resultado, temos um trabalho reduzido conceitualmente (privilegiando apenas a leitura de gráficos e tabelas) e pouco articulado com os demais blocos de conhecimentos matemáticos, inviabilizando muitas vezes a significação e compreensão de situações sociais.

Neste texto buscamos compreender de acordo com nosso referencial teórico, o processo de implementação da Estatística em uma turma de $9^{\circ}$ ano do Ensino Fundamental, mediado por um recurso tecnológico, o Excel, orientados pelo nosso questionamento inicial: Quais os limites e as possibilidades observadas em uma prática de educação estatística realizada no Ensino Fundamental mediada por recursos tecnológicos? Muitas realidades e possibilidades emergiram a partir da vivência desta pesquisa, o que nos coloca a refletir sobre as conclusões provisórias ao final deste estudo.

Os alunos apreciam e possuem capacidade de realizar atividades que tomem como ponto de partida a pesquisa. Esta abordagem de trabalho os envolve e os chama a participar da aula. Não houve problemas de indisciplina, havendo apenas a "desacomodação" e a curiosidade natural que uma prática diferenciada ocasiona. Neste sentido, a vivência de atividades de pesquisa, que envolvam coleta e análise de dados, onde seja possibilitada a participação ativa dos alunos na construção da proposta e lhes sejam possibilitados diferentes caminhos para sua efetivação, tornam as aulas de matemática instigantes e reflexivas.

Há muito que se desenvolver em relação aos conceitos estatísticos. Não há avanço conceitual quando são propostas apenas atividades de leitura gráfica. Para compreender a importância deste campo e fazer bom uso dos seus conhecimentos, os alunos devem aprender Estatística fazendo Estatística, pesquisando, organizando dados, representandoos em forma de gráficos, interpretando-os de forma crítica.

Diferentemente da hipótese que pressupomos no início do trabalho, não podemos afirmar que os alunos tiveram facilidade no uso do Excel. O desconhecimento tanto do software, como da terminologia relacionada à estatística, foram fatores que dificultaram o trabalho. Porém, pode-se afirmar que este recurso computacional contribuiu para que o centro do processo fosse a interpretação e as inter-relações possíveis a respeito do fenômeno pesquisado, minimizando o tempo dos cálculos e traçado de tabelas e gráficos. Os alunos mostraram-se motivados e envolvidos em estudar matemática com um recurso pouco utilizado nas aulas deste componente, o computador. O envolvimento no trabalho, a motivação ao explorar um novo recurso e a temática que partiu de realidade vivenciada, proporcionaram maior clareza na interpretação dos resultados produzidos. As dificuldades observadas no desenvolvimento desta prática, especialmente, pareceram advir do desconhecimento por parte dos alunos do que fosse o trabalho com dados estatísticos. Nossa proposta, apesar dos limites observados, foi muito exitosa, foi de fato significativa para os alunos, pois os colocou em uma posição ativa de aprendizagem.

\section{REFERÊNCIAS}

ANDRINI, Alvaro; VASCONCELOS, Maria José. Praticando matemática- 3ed-SP: editora do Brasil, 2012.

BRASIL. Ministério da Educação. Secretaria de Educação Fundamental. Parâmetros Curriculares Nacionais: Matemática $\left(1^{\circ}\right.$ e $2^{\circ}$ ciclos do Ensino Fundamental). Brasília: MEC/SEF, 1997.

BRASIL. Secretaria de Educação Média e Tecnológica. Parâmetros Curriculares Nacionais $+(\mathrm{PCN}+)$ - Ciências, matemática e suas tecnologias. Brasília: MEC, 2002. 
CAMPOS, Celso Ribeiro; WODEWOTZKI, Maria Lúcia Lorenzetti; JACOBINI, Otávio Roberto. Educação Estatística: teoria e prática em ambientes de modelagem matemática. Belo Horizonte: Autêntica Editora, 2011. (Coleção Tendências em Educação Matemática)

CARNEIRO, Vera Clotilde GARCIA. Engenharia didática: um referencial para ação investigativa e para formação de professores de Matemática. Zetetike, Campinas-

UNICAMP, v. 13, n. 23, 2005, p. 85-118. Disponível em: http://www.ufrgs.br/espmat/disciplinas/midias digitais II 2014/modulo III/ENGENH ARIA ZETEIKE2005.pdf. Acesso em 20 de out de 2015.

CAZORLA, Irene Mauricio; KATAOKA, Verônica Yumi; SILVA, Cláudia Borimda.Trajetórias e Perspectivas da Educação Estatística no Brasil: um olhar a partir do GT12. In:.LOPES, Celi Espasandin; COUTINHO, Cileda de Queiroz e Silva; ALMOULOUD, Saddo Ag.. (org.). Estudos e reflexões em Educação Estatística. Campinas: Mercado de Letras, 2010. p. 19-44. (Série Educação Estatística em Foco)

COUTINHO, Cileda de Queiroz e Silva.; ALMOULOUD, Saddo Ag.; SILVA, Maria José Ferreira. O desenvolvimento do letramento estatístico a partir do uso do GeoGebra: um estudo com professores de matemática. REVEMAT. Florianópolis, SC, v. 7, n. 2, 2012. Disponível em: <http://dx.doi.org/10.5007/1981-1322.2012v7n2p246 >. Acesso em: 07 de dez. 2015.

ESTEVAM, Everton José Goldoni; KALINKE, Marco Aurélio. Recursos tecnológicos e ensino de estatística na educação básica: um cenário de pesquisas brasileiras. Revista Brasileira de Informática na Educação, Volume 21, Número 2, 2013.

LOPES, Celi Aparecida Espasandin; MORAN, Regina Célia Carvalho Pinto. A estatística e a probabilidade através das atividades propostas em alguns livros didáticos brasileiros recomendados para o ensino fundamental. Anais da Conferência Internacional: Experiências e Perspectivas do Ensino da Estatística - Desafios para o século XXI. (p. 167-174) Florianópolis, 20,21 e 22 de setembro de 1999.

LOPES, Celi Aparecida Espasandin. Literacia Estatística e INAF 2002. In: FONSECA, Maria da Conceição Ferreira Reis (org.). Letramento no Brasil: habilidades matemáticas: reflexões a partir do INAF 2002. São Paulo: Global; Ação Educativa Assessoria, Pesquisa e Informação; Instituto Paulo Montenegro, 2004. p. 187-197.

. O ensino da estatística e da probabilidade na educação básica e na formação dos professores. Cadernos Cedes, Campinas, v. 28, n. 74, p. 57-73, jan./abr. 2008.

. Os desafios para a Educação Estatística no currículo da Matemática. In:LOPES, Celi Espasandin;COUTINHO, Cileda de Queiroz Silva de; ALMOULOUD, Saddo Ag. Estudos e reflexões em Educação Estatística. Campinas: Mercado de Letras, 2010. p. 47-64. (Série Educação Estatística em Foco).

. A educação estocástica na infância. Revista Eletrônica de Educação, v 6, n1, maio 2012. Artigos ISSN 1982-7199.

PASTORIO, Dioni Paulo; SAUERWEIN, Ricardo Andreas. O papel do computador em atividades didáticas: um olhar para o ensino de física. Renote novas Tecnologias na Educação. V.13 Nº1, julho, 2015.

SILVA, Rodrigo Sychocki; BARONE, Dante Augusto Couto; BASSO, Marcos Vinicios de Azevedo. O uso do Geogebra como ferramenta para construção de conceitos matemáticos: um primeiro estudo envolvendo Cadeias de Markov. Renote novas Tecnologias na Educação. V.12 Nº1, julho, 2014. 